\title{
3M Brazil ergonomics: a success story in the making
}

\author{
Larson, $\mathrm{N}^{\mathrm{a}}$, Oshiro, $\mathrm{R}^{\mathrm{b}}$ and Camargo, $\mathrm{O}^{\mathrm{c}}$ \\ ${ }^{a}$ Ergonomics, Corporate Safety Services, nllarson2@mmm.com, St.Paul, Minnesota, USA \\ ${ }^{\mathrm{b}}$ Ergonomics, Corporate Industrial Hygiene, rageraldooshiro@mmm.com, SP, Brazil \\ ${ }^{\mathrm{c}}$ Ergonomics, Corporate Industrial Hygiene, ofcamargo@mmm.com, SP, Brazil
}

\begin{abstract}
The aim of this project is to present two case studies and provide job assessment results, share implemented solutions, and provide information about realized cost and benefits. In this session, two cases studies, one from São José do Rio Preto and the other from Sumaré, will be presented. These projects won AEIA awards in 2009 and 2010, respectively. The projects describe the application of the Ergonomic Risk Reduction Program, which both improves worker's quality of life and productivity and product quality as well.
\end{abstract}

Keywords: Ergonomics Program, Risk Assessment, Participatory Ergonomics, Musculoskeletal Disorders (MSDs)

\section{Introduction}

The intent of the Ergonomics Program at $3 \mathrm{M}$ is to use ergonomics expertise consistently throughout the company to improve employee health and safety through development and utilization of standardized program elements, job analysis tools, and training programs. Ergonomics program requirements are defined in one element of an internal Global Health and Safety Plan.

One aspect of the program, 3M's Ergonomics Risk Reduction Process (ERRP), is a systematic process of identifying, prioritizing, assessing, and reducing unacceptable ergonomics risk in jobs throughout 3M's manufacturing and distribution operations, see Fig. 1. The ERGO Job Analyzer (EJA) tool provides a consistent, objective methodology to identify and quantify ergonomics risk exposure in all $3 \mathrm{M}$ manufacturing and distribution operations. The experience in Brazil demonstrates that the ERRP and ergonomics job assessment tool also help the company comply with the Brazilian Ergonomics Standard NR-17.

$3 \mathrm{M}$ recognizes ergonomics improvement through an Annual Ergonomics Innovation Award (AEIA). Over the past seven years, over 500 ergonomic improvements from around the globe have been submit- ted to an internal database that all EJA resources can access

These case studies provide job assessment results, solutions implemented, and information about costs and benefits realized. In this session, two case studies, one from São José do Rio Preto and the other from Sumaré, will be presented. These projects won 3M's Applied Ergonomics Innovation Awards (AEIA) in 2009 and 2010, respectively. The projects describe the application of the Ergonomics Risk Reduction Program, which both improved workers' quality of life and productivity and product quality as well by the application of the EJA tool.

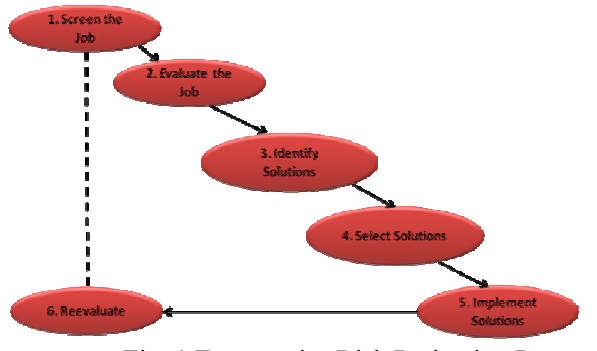

Fig. 1 Ergonomics Risk Reduction Process 


\section{Methodology}

The ERGO Job Analyzer tool [1] was used to identify the main risk factors. This tool is a standard ergonomic risk assessment applied at all $3 \mathrm{M}$ manufacturing operations. The location-specific ergonomic resources were responsible for identifying and implementing appropriate controls. We observed, filmed and photographed the activities of workers, wrote descriptions of the main tasks and interviewed the workers about the activities while we were observing them.

After modifying and improving the job, the improvement is documented in the on line ERGO Job Analyzer database.

\section{Case Studies}

\subsection{Case study 1: Cover band with rubber}

The opportunity was identified and prioritized according to 3M's Ergonomics Risk Reduction Process (ERRP) as an unacceptable workstation in a manufacturing area.

Employees' complaints in São José do Rio Preto were related to wrist repetitive movement during the band shaping production.

The activity consisted of manually opening the rubber ring on the outside of the 4-pin and then inserting the band inside it.

The EJA resource used the EJA tool to identify the high-risk factor correlating to the employees' complaints.

The hand grip force to open the rubber ring was 20 $\mathrm{kg}$ and it was repeated 1200 times per working day.

The worker's task is to put the rubber on the outside of the 4-pin and the band inside, after opening the pins. Employees also complained about the force necessary to complete the task. Due to the high risk of muscle injury in the execution of the process shaping the band, it was necessary to remove the hand grip movement.

A multidisciplinary team started working to improve the equipment to eliminate ergonomics risk and improve bands shaping production.

The force required by the employee and the awkward postures were eliminated through the process redesign and change in the way that the employee performs the task.

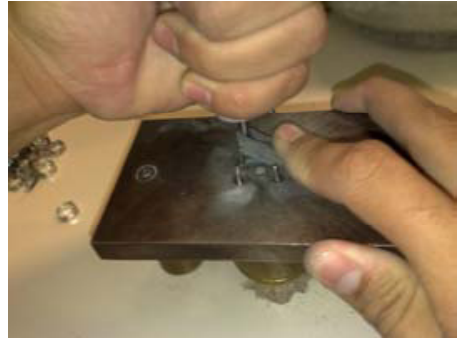

Figure 1: Old Machine-Manual Task

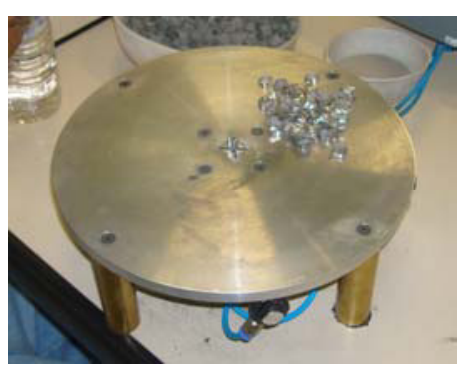

Figure 2: New Machine-semi-automatic

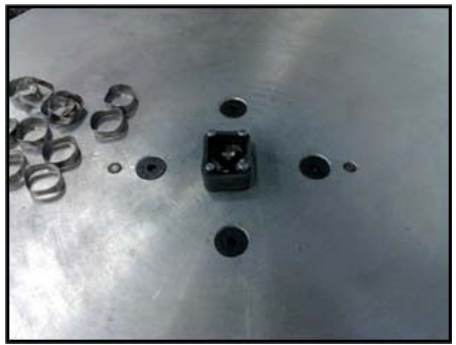

Figure 3: New Machine - After opening the 4-pins

A new EJA assessment was applied. The results: the high risk was totally eliminated, and productivity was increased by $100 \%$. Three old machines were eliminated by the new machine.

Workstations improvements will be implemented at the end of 2011 to eliminate remaining neck flexion and mechanical stress to arms concerns. In the meantime workers rotate during the workday, and, tasks will be automated to reduce or eliminate repetition. 


\subsection{Case study 2: Substitute wood pallets for lighter, corrugated cardboard pallets.}

Using 3M's Ergonomics Risk Reduction Process (ERRP), this opportunity also was identified and prioritized as an unacceptable workstation in the manufacturing area.

The main employees' complaint was about lifting the wood pallet. Approximately $50 \%$ of the workers working in packaging are women. The weight of the wood pallet was $25 \mathrm{~kg}$ and two workers would lift and carry the pallet from the storage area to the machine.

The main complaint was at the packaging process due to the weight of the wood pallet and about not having always a partner to lift and carry pallets during the shift. Operators can handle an average of 12 pallets per shift.

It was usual to bend forward $\left(\sim 60^{\circ}\right)$ to reach the pallet on the floor, and then to lift one edge of the pallet and pull it. When the stack is high (10 pallets), they must lift the pallet before pulling it to the machine. This task presents a safety issue.

The EJA resource applied the EJA to identify the high-risk factor and then to correlate it to the employees' complaints.

The weight of the pallet combined with its large awkward shape, and the distances it is often moved can combine to create a large moment arm which then creates very large forces on the spine.

The pain and discomfort caused by the pallet dimensions were present, and female workers demanded a lighter pallet.

A multidisciplinary team (packaging engineering, logistic, export and production) decided to replace the wooden pallets with cardboard ones for loads up to $200 \mathrm{~kg}$.

This new pallet consists of $70 \%$ of recycled material (pre-consumption paper) which contributes directly to minimizing residue disposal in landfills, recycling the pre-consumption scraps to generate a pallet with added value.

This cardboard pallet brings ergonomic benefits to the employee once the wood pallet weights $25 \mathrm{~kg}$, Fig 1 and the cardboard $3.6 \mathrm{~kg}$, Fig. 2.

The new pallet has mechanical strength, but is not waterproof. Therefore, the material should not be exposed to rain, and the content of the pallet needs to be wrapped in plastic. There is no limit for the use of the pallet if it is stored under appropriate conditions.

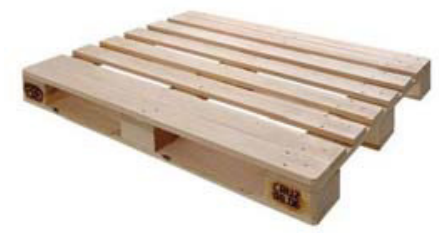

Fig. 1: $25 \mathrm{~kg}$ Wooden Pallet

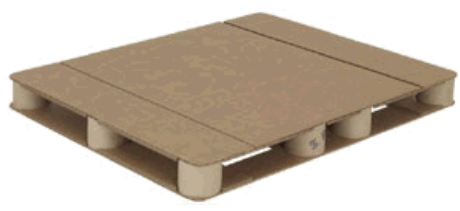

Fig. 2: $3.6 \mathrm{~kg}$ Cardboard Pallet (1200mmx1000mm)

The project was implemented initially in Brazil, and then in Argentina, Chile, Bolivia, Paraguay and Uruguay and was well accepted by those customers without any impact on the export operation.

Then, a new EJA assessment was conducted, showing that the discomfort and the pain were totally eliminated and employee' satisfaction increased.

The task of lifting and carrying the pallet is safe from the standpoint of ergonomics even if it occurs in extreme postures (worst situation) because the weight lifted is less than $7 \mathrm{~kg}$ (12 times per shift on average). And, the operator does not need a partner to help transport pallets.

Others savings from the improvement included a reduction of $38 \%$ in cost when purchasing the pallet, a savings of US $\$ 11,000$ in the first year, and an $85 \%$ reduction in carbon dioxide emission when compared to the wood pallet (less $\mathrm{CO} 2$ emission than wood pallet based).

\section{Conclusion}

These two case studies describe the application of the 3M Ergonomics Risk Reduction Program and the application of the EJA tool. The results generated by them as related to the worker's quality of life, and productivity and product quality were recognized by the Annual 3M Ergonomics Innovation Award.

Both improvements were a $3 \mathrm{M}$ development, and the investment was under 1,000 dollars for the first 
one. New job assessments were made to guarantee the ergonomics risks were eliminated and that the solution did not cause new problems.

The cross-functional team including workers was important to support the change. Involvement, communication and engagement of all are crucial for the results to be achieved. There would be resistance to change, if those involved were not fully aware about the importance of good posture in the workplace.

\section{References}

[1] Auburn Engineers, ERGO Job Analyzer Metric User’s Guide, 2003. 